\title{
A touch of indium
}

\author{
Catherine Renouf describes how indium went from being a rather inconspicuous element to one whose \\ role as a component of high-technology devices and gadgets may deplete its worldwide resources.
}

A

mysterious blue line in an 1863 atomic spectrum was the first indication that a new and unknown element was present within zinc ores. The indigo colour of that line gave its name to the new element, indium, and zinc ores are still its primary source today.

Ferdinand Reich (pictured) and Hieronymus Richter, who had observed the blue line and isolated the new element, were meant to present an ingot of indium at the World Fair in 1867; but, fearing its theft, they displayed a lead ingot instead. Members of the audience were probably easily fooled as these two very soft metals have similar appearances. What they could not have known at the time is that indium shares an unusual property with only one other element: tin. These two elements - neighbours in the periodic table - emit a crying sound when they are bent.

For 50 years after the World Fair, indium was merely a curiosity to be stored in chemists' cupboards. No-one had yet come up with a use for indium that justified persevering with a process-heavy purification, and the world's indium supply could be measured in grams.

It was during the Second World War that indium found a large-scale application: the malleable metal could be processed into thin films used to provide a lubricating coating for the bearings in aircraft engines. Lubrication, along with soldering - a second application that arose around the same time - remained its only uses until the late 1950s.

Worldwide demand increased from the 1970 s onwards. Indium, an efficient neutron absorber, was used to make control rods for nuclear reactors. The low melting points of its alloys (some as low as $50^{\circ} \mathrm{C}$ ) were useful for soldering, and also made for excellent fuses in heat regulators and sprinklers ${ }^{1}$. But the breakthrough discovery that sparked a widespread interest in indium was its use in the form of indium tin oxide (ITO). Today, the part played by ITO in most people's lives has led to element 49 being given a critical

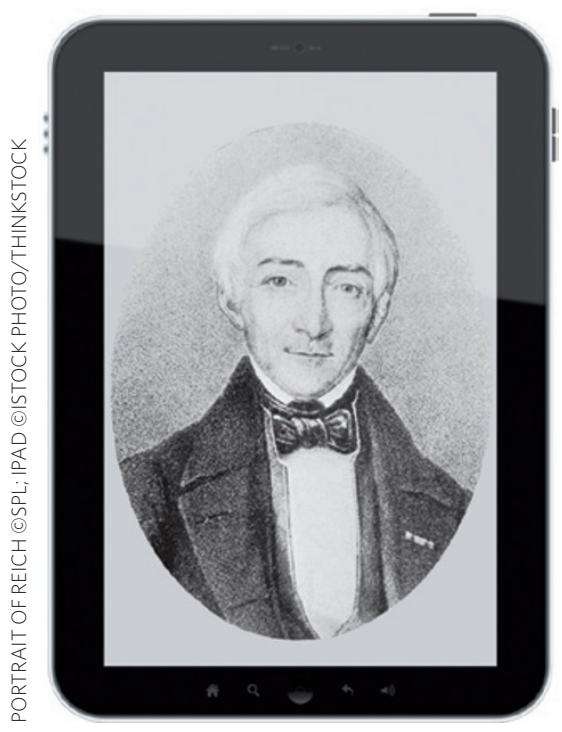

alarm for supplies depletion by the US Department of Energy ${ }^{2}$.

Indium is expensive and rare, and ITO is brittle and inflexible, yet overcoming these issues has allowed us to produce muchprized gadgets: our touchscreen devices, smartphones and liquid-crystal-display televisions. ITO is a unique material in that it is both electrically conducting and, crucially for all of these uses, optically transparent ${ }^{3}$. In addition, it is an important component of most solar cells, whatever their bulk composition, as transparent ITO is generally used to complete the electrical circuit at the front, light-absorbing surface ${ }^{4}$.

This transparency in the visible part of the spectrum arises from its wide bandgap at 3.3-4.3 eV; when it is used as a thin film, its transmission of visible light and electrical conductivity are both high enough for ITO to be put to use in touchscreen applications. The first such devices consisted of two separated layers of ITO that were joined through a stylus, but modern devices have evolved to exploit the user's electrically conducting finger instead, which makes for a more user-friendly — and a more spectacular - experience. Touching the ITO layer on the screen changes its capacitance at that particular position, which in turn sends a signal to the device.

The current touchscreen market is rapidly growing, and although the worldwide stores of indium are unknown - because it is still only a by-product from mining other metals, mostly zinc and tin it is estimated that there will only be enough indium to supply our growing needs until 2020. We can therefore expect it to become increasingly expensive as its rarity escalates.

Rollable displays are often touted as the next ground-breaking development in computing, a development for which the simple properties of ITO are not well suited. Whereas ITO's brittleness is not a problem in smartphones with an expected usage of a couple of years, and is acceptable for robust tablets and e-readers with slightly longer lifetimes, it will not transfer well to flexible or rollable devices. This new endeavour is sparking research into semiconductors that are indium-free, such as carbon nanotubes and graphene $e^{5}$, which can only be a good thing if we are to preserve our stock of this scarce metal, and maintain its availability — at affordable prices - for solar cells for green electricity generation.

Chemists played a large part in the development of ITO and all its uses, and we must now also lead the way in the search for its alternatives.

This essay was selected as a winning entry in our writing competition; see http://go.nature.com/oi187X

\section{CATHERINE RENOUF is a PhD student at} the School of Chemistry, University of St Andrews, North Haugh, St Andrews, Fife, KY16 9ST, UK.

e-mail: clr43@st-andrews.ac.uk.

\section{References}

1. Downs, A. J. Chemistry of Aluminium, Gallium, Indium and Thallium (Blackie Academic and Professional, 1993).

2. US Department of Energy. Critical Materials Strategy Summary (US Government Printing Office, 2010).

3. Tahar, R. B. H., Ban, T., Ohya, Y. \& Takahashi, Y. J. Appl. Phys. 83, 2631-2645 (1998).

4. Krebs, F. C., Spanggard, H., Kjær, T., Biancardo, M. \& Alstrup, J. Mater. Sci. Eng. B 138, 106-111 (2007)

5. Yen, M-Y. et al. Carbon 49, 3597-3606 (2011). 